\title{
An Investigation of the Effectiveness of Dialogue Shadowing Technique (DST) on Iranian Intermediate EFL Learners' Conversation Ability
}

\section{Julia Fouladi Nashta ${ }^{1}$, Ramin Rahimy ${ }^{1 *}$}

* Correspondence:

Rahimy49@yahoo.com

${ }^{1}$ Department of English Language,

Tonekabon Branch, Islamic Azad

University, Tonekabon, Iran

Received: 3 November 2017

Accepted: 31 January 2018

Published online: 20 June 2018

\begin{abstract}
The aim of the current study was to investigate whether L2 dialogue shadowing practice would have an effect on Iranian intermediate EFL learners' conversation ability. For this purpose, 30 Iranian intermediate EFL learners at Padideh language center participated in the experiment of the study. The participants were divided into two groups of 15 who were assigned to the experimental and control group of the study randomly. A pretest of conversation ability was administered to both groups, the experimental group received 10 sessions of teaching L2 conversation as well as dialogue shadowing technique (DST) while the control group received a placebo, in other words, teaching L2 conversation via existing method. After the treatment, the same test was administered as posttest to both groups of study. The data obtained from the tests in this study were analyzed via independent sample T-test between performance of the groups, and the paired-sample T-test was used between the pretest and posttest of each group to show the progress. The results revealed that Iranian EFL learners in the experimental group performed better and received higher score in conversation test after 10 sessions of treatment.
\end{abstract}

Keywords: dialogue, shadowing, EFL learners, conversation, speaking 


\section{Introduction}

Language is something that people do in their daily lives and something they use to express, create, and interpret meanings and to establish and maintain social and interpersonal relationships. If language is a social practice of meaning-making and interpretation, then it is not enough for language learners just to know grammar and vocabulary. They also need to know how that language is used to create and represent meanings and how to communicate with others and to engage with the communication of others. This requires the development of awareness of the nature of language and its impact on the world (Svalberg, 2007).

Speaking in a second language (L2) involves the development of a particular type of communication skills. Because of its circumstances of production, oral language tends to differ from written language in its typical grammar, lexical, and discourse patterns. In addition, some of the processing skills needed in speaking differ from those involved in reading and writing (Bygate, 2002).

Speaking is an interactive process of constructing meaning that involves producing, receiving, and processing information. Its form and meaning depend on the context in which it occurs, including the participants themselves, their experiences, the physical environment, and the purposes for speaking. It is often spontaneous, open-ended, and evolving. However, speech is not always unpredictable. Speaking requires that learners not only know how to produce specific points of language such as grammar, pronunciation, or vocabulary (linguistic competence), but also that they understand when, why, and in what ways to produce language (sociolinguistic competence) (Nunan, 1999).

Arguelles (2010) in his site notes that shadowing is simultaneously echoing a recording of foreign language audio that accompanies a manual of bilingual texts. The tendency of listeners when repeat the words what they heard to stimulate their episodic memory by storing numerous, independent memory for every words. Rost (2005) defines shadowing as a method using direct or paraphrased repetition, in which listener is asked to repeat what the speaker says, in the same language, either verbatim, or in close paraphrase. Another definition of shadowing is the on-line immediate process of repeating speech, while repeating is an off-line task because it provides learners with silent pauses to reproduce speech.

\section{Review of the Literature}

Oral proficiency is a student's ability to speak a language in real-life settings, outside of the classroom. Nowadays English is one of the most spoken languages in the world (Rönnerdahl \& Johansson, 2005). Its importance is inevitable. According to Rönnerdahl and Johansson, it has been suggested that as much as $99 \%$ of all communication is spoken and by this we can understand the importance of spoken language.

According to Rahimy and Asaei (2012) quoting from Brown (2000), communication may be regarded as a combination of acts, a series of elements with purpose and intent. Communication is 
not merely an event, something that happens; it is functional, purposive, and designed to bring about some effect-some change, however, subtle or unobservable-on the environment of hearers and speakers. Communication is a series of communicative acts or speech acts which are used systematically to accomplish particular purposes. Researchers have since been led to examine communication in terms of the effect that utterances achieve. That effect has implications for both the production and comprehension of an utterance; both modes of performance serve to bring the communicative act to its ultimate purpose. Second language learners need to understand the purpose of communication, developing an awareness of what the purpose of a communicative act is and how to achieve that purpose through linguistic forms.

According to Palmér (2010), oral language is students' main way of communicating and it is a very important part of their learning process. It is something that can be applied to all foreign language teaching, where the aim is for the students to develop their communicational skills. Therefore, the theoretical framework of the current study takes the speaking as a process and emphasizes the classroom activities needed to teach and learn speaking. Chastain (1988) discusses how to develop classroom speaking skills by underlining what is possible to be employed in the classroom including attitudes, language forms, and other facilities.

There is one assumption in second language acquisition research that language is acquired through conversation (Hatch, 1978; Sato, 1986; Swain, 1985). Hatch (1987) asserted that "one learns how to do conversation, one learns how to interact verbally, and out of this interaction syntactic structures are developed." Tasks that promote conversation therefore facilitate language acquisition. Swain (1986) has supported conversation practice in the classroom on the grounds that it promotes acquisition since oral interaction provides learners with the opportunity to push to the limit of their emerging competence. Long and Porter's review (1985) also indicated that from a psycholinguistic point of view, interlanguage talk, interaction between non-native speaking learners, is conducive to interlanguage development.

However, we can see that within this view, the teaching of conversation is a means to an end (language acquisition), and not an end in itself. The result is language being acquired, not enhanced conversation skills. While the goal of language acquisition is certainly crucial, it is important that teachers should be able to tell what an activity labeled "oral" or "conversation" actually practices. They should be able to distinguish between structural or fluency practice carried out by way of dialogues, and activities that teach and practice the skills for taking part in a conversation in the target language.

The main purpose of teaching conversation is to improve the students' communicative competence and the ability of learners to express themselves accurately and appropriately in different situations. In order to develop their conversation abilities in another language, L2 learners need to have an adequate vocabulary, pronounce words correctly, use word and sentence stress, organize their thoughts in a meaningful and logical sequence, access and use the language quickly, and confidently master the syntax. 
Developing the ability to speak in a second language involves the development of communication skills. Oral language and oral processing skills are different from reading and writing skills. Conversation is an interactive process of constructing meaning that involves producing, receiving, and processing information. It can mean to pronounce correctly (linguistic competence) or to understand and produce language effectively (communicative competence).

According to Lee and Patten (2003), L2 learners must develop interactive skills and the ability to negotiate the meaning. Both these skills require a learner to speak correctly and to be understood correctly by their interlocutor. This concept of communicating meaning via expression, and interpreting and negotiating meaning in a given context has also been reiterated by Savignon (2005). These opinions regarding expression and interpretation of meaning in language in its oral form include correct pronunciation patterns in the L2. To this effect, the learners must take the initiative and responsibility to work towards good pronunciation in which the dialogue shadowing techniques would help to improve these kinds of abilities.

According to Costa, Pickering, and Sorace (2008), a dialogue (or conversation) is a collaborative action usually aimed at exchanging information. Given that dialogue is an extremely common and natural activity, models of speech processing should try to understand the mechanisms involved in it. In fact, it may well be that our cognitive machinery is better designed for dialogue than for processing language in an isolated context.

\subsection{Shadowing}

Hamada (2012) also states that shadowing was originally used for training interpreters. Shadowing has also long been used explicitly as an exercise to enhance simultaneous interpreters' timing, listening, and short-term memory skills before they even start translating. Lambert (1992) defined shadowing as a paced, parrot-style auditory tracking task, conducted with headphones. Rather than a passive activity, however, shadowing is an active and highly cognitive activity in which learners track the heard speech and vocalize it as clearly as possible at the same time that they hear it.

Shadowing is not a new method; it is firstly used as interpreting method. Recently, it is adopted as instruction method in language teaching. Lambert (1992) says "technically speaking, shadowing is a paced auditory tracking task which involves the immediate vocalization of auditory presented stimuli, i.e. word-for-word repetition, in the same language, parrot-style, of a message presented through headphones." In shadowing, listener echoes the words they hear at the same time with the speaker.

According to Murphey (1995), there are varieties of shadowing: lecture shadowing, reading shadowing, and conversational shadowing which may go from complete to selective and interactive shadowing. In lecture shadowing, listeners shadow silently in their heads what a speaker says. In all the other examples, shadowing can be done out loud or silently to any degree. In reading shadowing, one student reads a passage while a partner shadows. 
Related pedagogical shadowing tasks (for getting use to doing it, for turning on and experimenting with the brain). Examples:

a. Lecture shadowing (silently inside the head) of teachers and other speakers. (Also possibly out loud with radio \& video.)

b. Pair reading shadowing, out loud-for getting partners to adjust.

c. Song shadowing, repeating as a background chorus would.

These forms of shadowing could also span the continuum from COMPLETE to SELECTIVE shadowing. Note also that the first may be done by some students unconsciously and the last is done by a lot of natives naturally.

Nicholson (1990) mentioned that there are three types of Shadowing: Phonemic Shadowing, Phrase Shadowing, and Adjusted lag Shadowing. Their differences are described below.

1. Phonemic Shadowing involves repeating each sound as it is heard, without waiting for the completion of meaning unit, or even completed word, so that the shower remains right 'on top' of the speaker. The instructors ask learners to stay as close behind the speaker as they can.

2. Phrase Shadowing involves repetition of the speech at longer pauses. In the form of shadowing, those who shadow generally wait for a phrase or chunk of meaning before they begin their repetition task. In phrase shadowing, students are instructed to maintain a lag which will allow you to identify an idea before shadowing.

3. Adjusted Lag Shadowing seems more difficult than phonemic shadowing. It does not require that the students listen for a unit of meaning before repeating it simply stipulates that repeaters must stay the required number of words behind the speaker. For adjusted lag shadowing, trainees are told to consciously stay between five to seven or, perhaps, seven to ten words behind the speaker.

With the present discussion of shadowing varieties, we can note that phonemic shadowing is easier than phrase or adjusted lag shadowing because phonemic shadowing does not need to identify meaningful units in the sentence or consciously stay behind the speaker for several words at a stable pace.

\section{Statement of the Problem}

According to Rahimy and Asaei (2012) quoting from Canale and Swain (1980) and Bachman (1990), proficiency in a second language is one of the most fundamental concepts in Applied Linguistics, and accordingly its character is the subject of ongoing and intense debate. Often this debate is about competing theories or models of second language proficiency and its development, as in the influential discussions by Canale and Swain (1980) and Bachman (1990). In case a second language learner succeeds in attaining proficiency, s/he will be able to get involved in an act called communication. 
There are different linguistic and non-linguistic factors which influence learners' speaking in English as a non-native language. Each factor can constitute a facilitating factor or a problem for learners' speaking in English. Different learners from different geographical entities and linguistic backgrounds face different problems in their efforts aimed at achieving a measure of proficiency in the skill of speaking in English. Persian-speaking EFL learners and students in the Iranian context face their own unique set of linguistic and non-linguistic problems while striving to come to grips with English language skills, including the skill of speaking.

In order to suggest a practical guideline for eliminating the L2 speaking problems, a lengthened literature can be reviewed, in which the effect of numerous techniques and tasks has been investigated. However, the present article aims to follow specific objectives as investigating of the effectiveness of dialogue shadowing technique (DST) on Iranian intermediate EFL learners' conversation ability. Along with these studies, the current research is to examine the dialogue shadowing features in the discussion section of English conversation by Persian learners to answer the following question and the findings will help teachers of English language to understand the strengths and weaknesses of learners, help learners to master the language and their weaknesses in regard to conversation ability, and help material developers to provide proper instructions for them. The findings of this study would also pave the way for successive researchers to put different aspects of dialogue shadowing technique used in conversation instruction.

\section{The Research Question}

Based on the problem stated and the background presented, the current study aimed to find answer to the following question:

Does dialogue shadowing technique have any effect on Iranian intermediate EFL learners' conversation ability?

\section{Hypothesis of the Study}

Accordingly, the null hypothesis of the study is as follows:

H0: Dialogue shadowing technique does not have any effect on Iranian EFL learners' conversation ability.

\section{Methodology}

\subsection{The Design of the Study}

This study followed a pre-test-post-test intact group design. First, there was an intact subject selection. Second, the participants were assigned randomly into two groups of experimental $(\mathrm{N}=15)$ and control $(\mathrm{N}=15)$. A pretest of $\mathrm{L} 2$ conversation administered to both groups of the study and then, the experimental group received 10 sessions of teaching dialogue shadowing while the control group received a placebo (teaching L2 conversation via the existing method). Next, a posttest of L2 conversation administered to both groups of the study and finally the data were analyzed. The design of the study has been summarized in figure 1 below: 


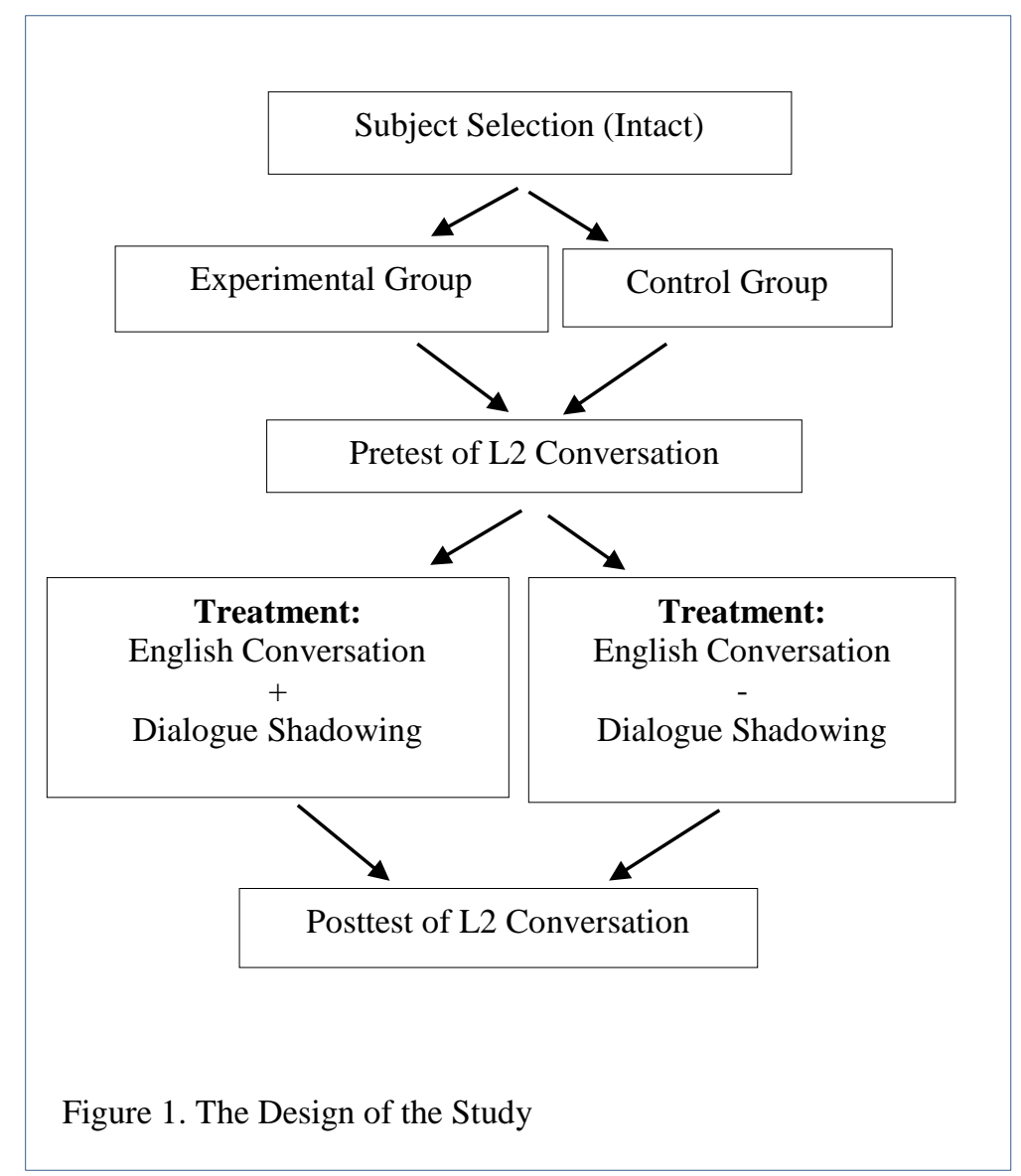

\subsection{Participants}

The participants of the current study were 30 Iranian intermediate EFL learners who were selected intactly. All the participants were intermediate level students studying in Padideh Language Center in Tonekabon, Iran. All of them were native of Persian language. In fact, the participants who had scored at least one standard deviation below the mean were assigned randomly in to two groups of experimental $(\mathrm{N}=15)$ and control $(\mathrm{N}=15)$.

\subsection{Instruments}

The materials of the current study were three sorts. The material for the pretest of the study was an interview with the participants based on certain questions, their voice were recorded, then scored on the basis of a researcher-made checklist of conversation scoring. All target questions were asked and the participants answered all of them. The second material was the treatment of the study which contained a list of dialogues to be played-back to and shadowed by the participants within 10 sessions, and the third one was the post-test of L2 conversation ability. The scoring procedure will be explained later in procedure section.

The researchers interviewed participants based on a list of predetermined questions and dialogues for instance how to greet each other, how to address people, talk about different manners such as extrovert and introvert people, name some etiquette for international business meetings, talk about 
food and taboo conversation topics, name some dental problems and symptoms for different diseases, talk about different topics such as children, technology, journey, shop, and some other activities, and their voices were recorded and scored.

Then researchers used a list of dialogues and conversation models according to Top Notch series to be played-back and shadowed by the participants of experimental group within 10 sessions. The treatment for the experimental group in this study included a list of dialogues and conversation models which were selected from the book 'Top Notch' (Saslow \& Ascher, 2006). The researchers taught L2 conversation through different examples and explanation as well by repetition within 10 sessions. The post-test which was administering after treatment sessions was equal in all aspects of pre-test. The researchers interviewed the participants again. The questions were responded and the dialogues were repeated again and they were scored by instructors. The researchers estimated the participants' scores and evaluated their improvements.

\section{Data Collection}

From Padideh Language Center, 30 participants intactly were selected as an assigned randomly to an experimental and a control group. The participants took a pre-test and a post-test. The researchers conducted an interview before the research gets start. This could be a flexible way of collecting data. So the researchers interviewed participants based on some predetermined questions, their voice were recorded and scored. Then the researchers tried to estimate the participants' vocabulary, speaking and listening skills for accuracy by two experienced teachers according to Padideh Language Center's chart and the focus was on correct pronunciation, fluency, and grammar of the target language. The marks in both tests were out of 20. During the project, the researchers used a list of dialogues to be played-back and shadowed by the participants of the experimental group within 10 sessions but the second group as control group did not. They were a little familiar with various kinds of intonation and pronunciation. After 10 sessions of teaching, at the end of this training program, the post-test was given to both experimental and control groups, then the researchers estimated participants' vocabulary, listening, and speaking skills again for evaluating their improvements.

\section{Data Analysis and Findings}

\subsection{The Descriptive Analysis of the Data}

The descriptive analysis of the obtained data in the current study is concerned in this section. It was done using SPSS software. The following table shows the descriptive analysis of the data between the pre-test and the post-test of the experimental group of the study. 
Table 1. Descriptive analysis of the experimental group of the study

\begin{tabular}{|c|c|c|c|c|c|}
\hline & & Mean & $\mathrm{N}$ & $\begin{array}{l}\text { Std. } \\
\text { Deviation }\end{array}$ & Std. Error Mean \\
\hline \multirow[t]{2}{*}{ Pair 1} & Posttest ex & 17.9333 & 15 & 1.57963 & 0.40786 \\
\hline & Pretest ex & 14.5333 & 15 & 2.55976 & 0.66093 \\
\hline
\end{tabular}

As is indicated above (Table 1), the number of subjects participated in the study has been 15 in the experimental group. The mean for the pre-test EX (pre-test of the experimental group) was shown to be 14.5333 as compared to the mean for the post-test EX (post-test of the experimental group) which was 17.9333. The standard deviations obtained for the experimental group show more variability among the scores of pre-test EX rather than post-test EX scores. As a result of this fact, subjects' post-test score in the experimental group may be more homogenous after going under the treatment.

The proceeding table shows the descriptive analysis of the data between the pre-test and post-test of the control group of the study.

Table 2. Descriptive analysis of the control group of the study

\begin{tabular}{|c|c|c|c|c|c|}
\hline & & Mean & $\mathrm{N}$ & $\begin{array}{l}\text { Std. } \\
\text { Deviation }\end{array}$ & Std. Error Mean \\
\hline \multirow[t]{2}{*}{ Pair 1} & Posttest con & 16.3333 & 15 & 1.83874 & 0.47476 \\
\hline & Pretest con & 15.0000 & 15 & 2.85357 & 0.73679 \\
\hline
\end{tabular}

As is indicated above (Table 2), the number of subjects participated in the study has been 15 in the control group. The mean for the Pre-test CON (pre-test of the control group) was shown to be 15.000 as compared to the mean for the Post-test CON (post-test of the control group) which was 16.333. The standard deviations obtained for the control group show more variability among the scores of pre-test CON rather than post-test CON scores. As a result of this fact, subjects' posttest score in the control group may be more homogenous after going under the treatment. 


\subsection{The Inferential Analysis of the Data}

This section elaborates the inferential analysis of the data which are obtained in the study. It was done using Statistical Package for Social Science (SPSS). The following tables summarize the inferential analysis of the data of the current study.

Table 3. Independent Samples T-test result of the study

t-test for Equality of Means

\begin{tabular}{lllll} 
& & t & Df & Sig. (2-tailed) \\
\hline Conversation & Equal variances assumed & 2.556 & 28 & 0.016 \\
& $\begin{array}{l}\text { Equal variances } \\
\text { assumed }\end{array}$ & ${ }^{2.5}$ 2.556 & 27.378 & 0.016 \\
\hline
\end{tabular}

As is pointed out in Table 3, the t-value of the study was calculated between the post-tests of conversation in the experimental group and the control group. The observed $t$ value was calculated as to be 2.556 which is higher than the critical $t$ value $(\mathrm{t}=2.048)$ and the degree of freedom was $27.378(\mathrm{df}=27.378)$, and also the level of significance was calculated as to be .016 which has been used in rejection or support of the hypothesis of the study in proceeding section.

Paired sample T-test was run to determine students' progress within groups. It showed the participants' progress between pre-test and post-test in the following table.

Table 4. Paired Samples T-test result for the experimental group

t df Sig. (2-tailed)

$\begin{array}{lllll}\text { Pair } 1 & \text { Posttest ex - pretest ex } & 6.492 & 14 & 0.000\end{array}$

According to Table 4, which elaborates the results of paired samples test correlations between the pre-test and the post-test scores of the experimental group; the sig. value (.000) is smaller than 
0.05 which means the difference is significant. The observed $t$ value is $6.492(t=6.492)$ that is higher than the critical $\mathrm{t}$ value $(\mathrm{t}=2.145)$. Additionally, the degree of freedom was $14(\mathrm{df}=14)$. This rejects the null hypothesis. Based on the result of paired samples T-tests, the progress was statistically significant for experimental group. It means that the experimental group of the study made a distinct improvement in comparison to the control group.

Table 5. Paired Samples T-test result for the control group

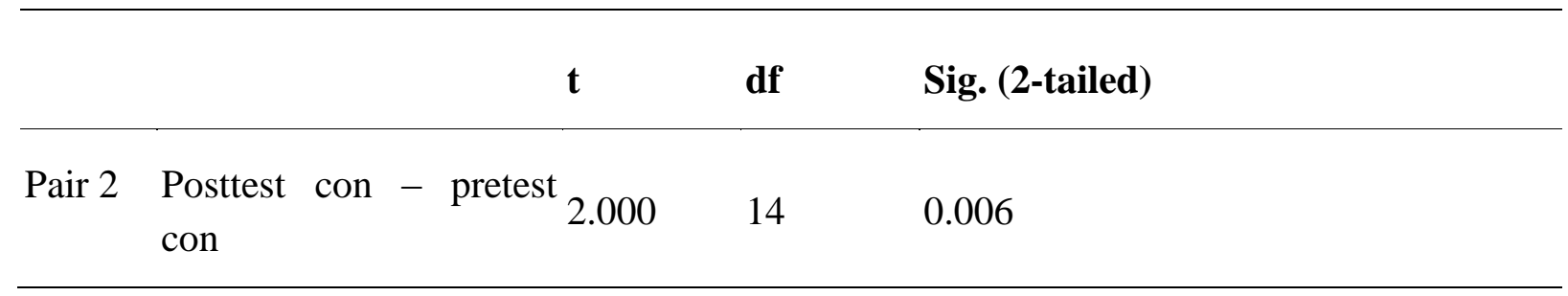

As is shown in Table 5, the sig. value of the control group of the study was calculated to be 0.006 (sig. value $=0.006)$. The observed $t$ value is $2.000(t=2.000)$ that is lower than the critical $t$ value $(\mathrm{t}=2.145)$. Additionally, the degree of freedom was $14(\mathrm{df}=14)$.

\section{Discussion}

The results and findings of the study revealed that using DST (dialogue shadowing technique) in teaching conversation leads to a better performance of language learners in L2 conversation accuracy tests. Such a finding is compatible with the research made by Nicholson (1990) that shows how shadowing technique makes learning of accurate conversation easier. He has also pointed out that speech shadowing is an experimental technique in which subjects repeat speech immediately after hearing it (usually through earphones). Words repeated during the practice of shadowing imitate the parlance of the overheard words more than the same words read aloud by that subject. The technique is also used in language learning. Speech shadowing was first used as a research technique by the Leningrad Group led by Chistovich in the late 1950s. Furthermore, the findings view that Shadowing Techniques have been used in English as a second or foreign language teaching. So, the results of this study can have contributions towards a relationship between language instruction and language use due to focusing on shadowing technique in conversation teaching rather than pure instruction.

Given the fact that teaching L2 oral proficiency is a rather tedious task since the speaking skill is a productive one, many teachers and testers have always tried to find efficient ways to teach conversation. Some of them try to teach conversation in isolation and some others teach it as integration with other skills such as listening. Few researches are conducted on using shadowing technique practices as tool in teaching conversation which can be beneficial in language teaching classroom, since it is simple, interesting, and effective way of the teaching that help learners 
improve their intelligibility. According to Costa, Pickering, and Sorace (2008), a dialogue (or conversation) is a collaborative action usually aimed at exchanging information. Given that dialogue is an extremely common and natural activity, models of speech processing should try to understand the mechanisms involved in it. In fact, it may well be that our cognitive machinery is better designed for dialogue than for processing language in an isolated context.

According to Hamada (2012), shadowing was used for training interpreters. It has also used as an exercise to increase simultaneous interpreters' timing, listening, and short-term memory skills before they begin translating. This view has been supported by Lambert (1992), indicating that shadowing as a paced, parrot-style auditory tracking task, carried out with headphones. Shadowing is an active and cognitive activity in which learners track the heard speech and vocalize it at the same time that they hear it. Generally speaking, interpreters' performance would be greatly influenced by the difficulty of the speech. As listening to speech with high difficulty degree, interpreters' comprehension would degrade, and interpreters have to put more effort into comprehension. In this situation, they do not have the ability to tackle the detailed message. Under such circumstances, they could only interpret key ideas in the speech. Therefore, the difficulty of a speech would influence the interpreters' performance (Chen, 2007).

\section{Conclusion}

Based on the results obtained from this study, a positive effect of certain tasks such as shadowing on Iranian EFL learners' conversation ability cab be concluded. Based on the difference between target conversation and L2 learners' conversation evidenced in the current study and others in literature, teachers should use activities and tasks such as dialogue shadowing techniques which help learners distinguish different words and pronounces. They can also make L2 learners aware of the importance of segmental aspects of speaking in conveying message and increase their ability to distinguish words that are different in only one sound or pronunciation. To this end, teachers can raise learners' awareness that if they fail to convey intelligibility because of their disability in distinguishing the suitable words, no communication would occur and they cannot be understood. Similarly, the findings of the study suggest that teachers can use dialogue shadowing technique prominently while teaching conversation. In countries such as Iran where there is few or no opportunities for L2 learners to have exposure outside the classroom or to speak with a native speaker to improve their conversation ability, there are various, simple, and efficient ways to teach conversation, as it is evident in the current study that shadowing technique is a good practice in teaching conversation.

Dialogue shadowing technique can be used as a means to solve conversation problems of EFL/ESL learners, and both of the teachers and learners can demonstrate high appreciation of pedagogical effectiveness of dialogue shadowing technique when they are used as either teaching or learning tools. The results of the study are more practical to Iranian situation of foreign language learning for those who face problems regarding their conversation competence. Accordingly, they are applicable to Iranian EFL learners at any level who feel the need of strengthening their knowledge 
of conversation patterns. Finally, the results of the study can be beneficial for material designers to develop new curricula for conversation teaching and also for EFL testers.

\section{References}

Arguelles, A. (2010). Guide to autodidactic foreign language study. Journal of Advances in English Language Teaching, 1(1), 12-23.www.foreignlanguageexpertise.com/foreign_language_study.html

Bachman, L. F. (1990). Fundamental considerations of language testing. Oxford. Oxford University Press.

Brown, D. H. (2000). Principles of language teaching and learning. Oxford University Press, (4th ed.). New York: Longman. (121-134)

Bygate, M. (2002). Effects of task repetition on the structure and control of oral language. In M. Bygate, P. Skehan \& M. Swain (Eds.), Researching pedagogic tasks. Second language learning teaching and testing, 23-49.

Canale, M., \& Swain, M. (1980). Theoretical bases of communicative approaches to second language teaching and testing. Applied Linguistics, 1, 1-47. doi: 10.1093/applin/I.1.1

Chen, Y. C. (2007). A study on the efficacy of consecutive interpretation training. Unpublished Master Thesis. National Changhua Normal University, Taiwan.

Costa, A., Pickering, M. J., \& Sorace, A. (2008). Alignment in second language dialogue. Language and Cognitive Processes, 23(4), 528-556. doi:10.1080/01690960801920545 URL: http://dx.doi.org/10.1080/01690960801920545

Hamada, Y. (2012). An effective way to improve listening skills through shadowing. The Language Teacher, 36(1), 3-10.

Hatch, E. (1978). Discourse analysis and second language acquisition. In E. Hatch (Eds), Second Language Acquisition (pp. 401-435), Rowley, Mass.: Newbury House.

Lambert, S. (1992). Shadowing. Meta, 37(2), 263-273. URI: id.erudit.org/iderudit/003378ar doi: 10.7202/003378ar

Lee, J. F., \& Van Patten, B. (2003). Making communicative language teaching happen (2nd ed.). New York: McGrawHill.

Long, M., \& Porter, P. (1985). Group work, interlanguage talk, and second language acquisition. TESOL Quarterly, 19(2), 207-228. doi: 10.2307/3586827 URL: http://www.jstor.org/stable/3586827

Murphey, T. (1995). Conversational shadowing for rapport and interactional language acquisition. In Proceedings of the 6th Conference on Second Language Research in Japan. International University of Japan, 42-65.

Nicholson, N. (1990). Strategy, innovation and performance. Journal of Management Studies, 27(5), 511-534. https://doi.org/10.1111/j.1467-6486.1990.tb00259.x

Nunan, D. (1999). Second language teaching and learning. Boston: Newbury House.

Palmér, A. (2010). Muntligt i klassrummet. Om tal, samtal och bedömning. Lund: Studentlitteratur.

Rahimy, R., \& Asaei, S. M. (2012). Audio texts and English speaking ability: Evidence from Iranian EFL learners. Academic Research International, 3(2), 607-616.

Rönnerdahl, G., \& Johansson, S. (2005). Introducing English pronunciation -Advice for learners and teachers. Lund: Student literature. 
Rost, M. (2005). L2 Listening. In E. Hinkel (Ed.), Handbook of research in second language teaching and learning (pp. 503-527). Mahwah, NJ: Erlbaum.

Saslow, J., \& Ascher, A. (2006). Top Notch series: English for today's world. White Plains, New York: Pearson Education.

Sato, C. (1986). Conversation and interlanguage development: rethinking the connection. In R. Day (Ed.), Talking to learn: Conversation in second language acquisition (23-45). Rowley, Mass.: Newbury House.

Savignon, S J. (2005). Cultures and comparisons: Strategies for learners. Foreign Language Annals, 38(3), 357-365. https://doi.org/10.1111/j.1944-9720.2005.tb02222.x

Svalberg, A. M. (2007). Language awareness and language learning. Language Teaching, 40(4), 287-308. https://doi.org/10.1017/S0261444807004491

Swain, M. (1985). Communicative competence: some roles of comprehensible input and comprehensible output in its development. In S. Gass, \& C. Madden (Eds.), Input in second language acquisition (235-253). Rowley, MA: Newbury House. 